\title{
correspondence
}

\section{Academics in Chile}

SiR,-The international scientific community must be aware of the dramatic condition of the Chilean academic community. The military authorities who have taken over the power in all Chilean universities issued new rules stipulating that:

"Any nomination or contract must from now on be considered strictly provisional. The Special Commission [installed by the military rectors] will propose renewals or cancellations of such contracts in each particular case.

All students must apply for reinscription ... The Special Commission will decide on the opportunity of accepting or rafusing such applications.

Any professor, administrative employee, technician or student suspected by civil or military courts will be immediately suspended ... Any one of them being sentenced will be dismissed; students will be permanently expelled from the Universities.

The same action will be taken towards those having answered citations from the courts ..."

This quotation is taken from an official statement issued by the new authorities in charge of one Chilean university on September 28, 1973. Analogous decisions have been made in all universities, including the Universidad Catolica de Chile. As a consequence of this, many professors or academic staff have lost their jobs. In the most favourable cases (such as that of professors on official leave or absence abroad), scientists "have been granted permission to present their resignation" (usually with retroactive effect). Many have been arrested, on an arbitrary charge or no charge at all, usually after anonymous denunciations of neighbours or colleagues. Many of them are still in prison and an official International Lawyer's Commission has presented evidence for many cases of physical torture. In La Serena, professors against whom no special charge could be found have been executed in spite of having been condemned to minor sentences (less than two months of imprisonment).

Several other members of the academic community have been executed without being permitted to present their defence.

In various universities, departments like geography, sociology, economics and biophysics have been completely dismantled.

These facts must be publicised and scientists all over the world should press governments and international organisations in order to prevent further repressive actions. In addition, there is an urgent need for help to academic people who already could, or will eventually be able to, leave the country. We have on record many excellent applications in all fields ranging from mathematics to social sciences.

All those able to offer laboratory space and positions, even on a temporary basis, should contact the Committee of Assistance to Chilean Scientists (CACS), by writing to $M$. Imbert, Collège de France, 75231 ParisCedex 5.

Yours faithfully, H. M. Gerschenfeld

Ecole Normale Supérieure,

Paris, France

\section{F. Gros}

F. JACOB

A. LWOFF

J. P. ChangeuX

Institut Pasteur, Paris, France

Masle

University of Copenhagen, Copenhagen, Denmark

P. WALL

University College,

London, UK

\section{North Sea oil}

SIR,-Although I agree with the opening paragraph of Eleanor Lawrence's article on the planning aspects of North Sea oil (Nature, 247, 416; 1974) I feel that the remainder of the article leaves much to be disputed.

What does Mrs Lawrence mean by 'getting the oil ashore as quickly as possible'? If she means seeing the oil flow as soon as possible then there is probably nobody against it. Already, nine platforms are in various stages of construction for the Auk, Beryl, Brent and Forties fields, and at least one or two other fields will be exploited using drilling rigs rather than production platforms. There is, therefore, no block to how quickly the first oil will come ashore. If, however, she means by 'the most extreme preservationists' those who are opposing the intended maximum rate of exploitation of this im. portant resource (as is current policy) then she is referring to no splinter group of cranks. It includes Liberals, Scottish Nationalists and a good number of Socialists who have all committed themselves against seeing oil used in this way.

It is, I would agree, right to criticise present planning procedures because they treat each separate proposal in isolation rather than in the context of a coordinated plan. This is plainly ridiculous. The advantage that the present system offers, however, is time to reflect. The technological situation in relation to oil extraction from the sea bed is changing so rapidly that there are real dangers that what seems essential today will be of historic interest in a couple of years' time. Thus although the Condeep gravity concrete structure is currently in favour (and if to be built in Britain, probably needs to be constructed at Loch Carron) this ignores the alternative deep-water platform designs already being offered by different companies at existing yards, ignores the recent innovations in 'floating' platforms announced recently and ignores the technology for seabed completions which it is expected will be erected for deep water cases within the next two years. It would be a tragedy if rushed decisions caused the destruction of a way of life at Loch Carron, especially if it were for only a short term return.

The real iniquity of the present system is that the objectors should be involved in costs of many thousands of pounds. This is not because of the law itself but because of government choice. Section 267, subsections 7 and 8 of the Town and Country Planning (Scotland) Act 1972 states clearly that costs may be awarded to the objectors but the Secretary of State for Scotland has consistently refused to consider doing this. Thus, although objectors must pay their costs from their earned and taxed incomes, development companies can offset their costs against profits before tax. At Dunnet Bay the objectors were faced with a bill of $£ 3,000$ while Chicago Bridge decided to go elsewhere. At Loch Broom, the Action Group incurred costs in setting up its case against the proposed development at Ullapool before Mowlem discovered that the site was unsuitable anyway. Meanwhile the taxpayer contributed to an environmental impact survey that was never needed. The main objectors at Drumbuie will be faced with bills of tens of thousands of pounds. There is a very clear case indeed, in the light of the special circumstances that oil developments present, for the proposing companies to be held responsible for costs of genuinely concerned objectors. Terence W. Hegarty

North Sea Oil Coalition,

2 Tayside,

West Ferry,

Dundee DD5 1DW, UK 